INTERDISCIPLINARIA ARCHAEOLOGICA NATURAL SCIENCES IN ARCHAEOLOGY

\title{
Orientation Patterns Characteristic for the Structure of the Ceramic Body of Wheel-thrown Pottery
}

\author{
Richard Thér ${ }^{1 *}$, Petr Toms ${ }^{2}$ \\ ${ }^{1}$ Department of Archaeology, Philosophical Faculty, University of Hradec Králové, Rokitanského 62, 50003 Hradec Králové, Czech Republic \\ ${ }^{2}$ Private researcher, Machovská Lhota 71, 54963 Machov, Czech Republic
}

\section{ARTICLE INFO}

\section{Article history:}

Received: $19^{\text {th }}$ February 2021

Accepted: $6^{\text {th }}$ October 2021

DOI: http://dx.doi.org/10.24916/iansa.2021.2.3

\section{Key words:}

orientation analysis

wheel throwing

pottery forming

image analysis

thin section petrography

\begin{abstract}
A B S T R A C T
The described analysis follows recent findings related to the orientation of particles and voids in a ceramic body that is characteristic for wheel-made pottery. The analysis is focused on the potential variability within wheel-throwing method and is based on an experimental collection that combines the factors of the experience and motor habits of individual potters and the vessel shape. The orientation of the components of a ceramic body is calculated for two sections: radial and tangential. The sections are analysed using optical microscopy. The calculated orientation and alignment reflect the throwing style of potters using the same forming method.
\end{abstract}

\section{Introduction}

During the past decade, we have been developing a methodology based on quantification of the orientation and alignment of the components of a ceramic body as one of the principal features reflecting pottery-forming techniques that are theoretically observable on every sherd (Thér, 2016; Thér et al., 2019; Thér and Toms, 2016). Many of the phenomena that occur on the surface of pottery fragments and can be related to pottery-forming practices are randomly preserved, and their interpretation is further complicated by the common practice of combining several techniques during the forming and finishing of vessels. One diagnostic attribute can, at least theoretically, be observed on every ceramic sherd - the orientation of the structure of the ceramic body. The relationship between forming techniques and the orientation of the components of the ceramic material has long been recognised (Balfet, 1953; Bordet and Courtois, 1967; Felts, 1942; Gifford, 1928; Linné, 1925, p.33; Shepard, 1956, pp.183-184). The application of physical force to the plastic clay during forming is the main factor affecting the alignment

\footnotetext{
*Corresponding author. E-mail: richard.ther@uhk.cz
}

of the components. The resulting orientation and alignment are characteristic of each forming method, although some orientation patterns might result from more than one fabrication process (for an overview of the assumptions for particular techniques see Berg, 2008, Figure 1; Carr, 1990; Courty and Roux, 1995, Table 1; Livingstone Smith, 2007, pp.88-146; Middleton, 2005, Figure 4.8; Pierret, 1995, pp.46-50; Roux, 2019, Figure 3.20; Rye, 1981, pp.58-89; Thér, 2020, Figure 9; Whitbread, 1996).

Measurement of the orientation refines the analysis of preferred orientation by defining the exact intervals of orientation variability for the individual forming techniques and their combinations. For the measurements, we selected two basic sections: sections perpendicular to the wall surface in the plane parallel to the vessel height (hereinafter referred to as a radial section) and sections tangential to the vessel wall cut through a core zone of the wall (hereinafter referred to as a tangential section). Originally, we captured three transects approx. $6 \mathrm{~mm}$ wide in each thin section at a magnification of 40 times in plane-polarised light using a standard petrographic microscope. The resultant images have a resolution of $1.09 \mu \mathrm{m}$. Then inclusions and voids were extracted using object extraction and separation methods in 
Table 1. Orientation analysis results for experimental samples taken in tangential and radial sections. MD - Mean direction, CSD - Circular standard deviation.

\begin{tabular}{|c|c|c|c|c|c|c|c|c|c|c|}
\hline \multirow{2}{*}{ Sample } & \multirow{2}{*}{$\begin{array}{c}\text { Min. } \\
\text { thickness }\end{array}$} & \multirow{2}{*}{$\begin{array}{c}\text { Max. } \\
\text { thickness }\end{array}$} & \multirow{2}{*}{$\begin{array}{l}\text { Diff. in } \\
\text { thickness }\end{array}$} & \multirow{2}{*}{ Shape } & \multirow{2}{*}{ Author } & \multirow{2}{*}{ Wheel } & \multicolumn{2}{|c|}{ Radial sections } & \multicolumn{2}{|c|}{ Tangential sections } \\
\hline & & & & & & & MD & CSD & MD & CSD \\
\hline 1 & 3797 & 4910 & 1113 & Bowl & Henry & Motorised & 7 & 35 & 28 & 36 \\
\hline 2 & 4048 & 5001 & 953 & Bowl & Henry & Motorised & 5 & 33 & 19 & 30 \\
\hline 3 & 3945 & 5125 & 1180 & Bowl & Henry & Motorised & 3 & 36 & 27 & 38 \\
\hline 4 & 4806 & 5807 & 1001 & Bowl & Henry & Motorised & 3 & 35 & 27 & 31 \\
\hline 5 & 4833 & 5617 & 784 & Bowl & Henry & Motorised & 3 & 39 & 41 & 23 \\
\hline 6 & 5022 & 5587 & 565 & Bowl & Henry & Motorised & 4 & 35 & 34 & 37 \\
\hline 7 & 3809 & 4265 & 456 & Bowl & Henry & Motorised & 4 & 39 & 22 & 31 \\
\hline 8 & 3492 & 4377 & 885 & Bowl & Henry & Motorised & 1 & 36 & 38 & 37 \\
\hline 9 & 3672 & 4415 & 743 & Bowl & Henry & Motorised & 4 & 33 & 25 & 34 \\
\hline 10 & 4080 & 4550 & 470 & Bowl & Henry & Motorised & 5 & 33 & 51 & 31 \\
\hline 11 & 4026 & 4318 & 292 & Bowl & Henry & Motorised & 7 & 33 & 38 & 35 \\
\hline 12 & 4043 & 4393 & 350 & Bowl & Henry & Motorised & 1 & 35 & 42 & 31 \\
\hline 13 & 3830 & 4021 & 191 & Bowl & Henry & Motorised & 1 & 32 & 39 & 38 \\
\hline 14 & 3672 & 3979 & 307 & Bowl & Henry & Motorised & 6 & 31 & 42 & 35 \\
\hline 15 & 3784 & 4373 & 589 & Bowl & Henry & Motorised & 7 & 30 & 23 & 30 \\
\hline 16 & 3616 & 4229 & 613 & Conical v. & Henry & Motorised & 15 & 28 & 21 & 33 \\
\hline 17 & 3311 & 3742 & 431 & Conical v. & Henry & Motorised & 19 & 26 & 37 & 34 \\
\hline 18 & 3510 & 4471 & 961 & Conical v. & Henry & Motorised & 14 & 27 & 31 & 35 \\
\hline 19 & 4372 & 5651 & 1279 & Conical v. & Henry & Motorised & 14 & 34 & 39 & 38 \\
\hline 20 & 3956 & 5156 & 1200 & Conical v. & Henry & Motorised & 9 & 33 & 45 & 33 \\
\hline 21 & 4040 & 5329 & 1289 & Conical v. & Henry & Motorised & 13 & 32 & 35 & 35 \\
\hline 22 & 4395 & 4700 & 305 & Conical v. & Henry & Motorised & 30 & 42 & 18 & 17 \\
\hline 23 & 3934 & 4593 & 659 & Conical v. & Henry & Motorised & 24 & 39 & 19 & 21 \\
\hline 24 & 4197 & 4538 & 341 & Conical v. & Henry & Motorised & 25 & 40 & 19 & 20 \\
\hline 25 & 4446 & 4970 & 524 & Conical v. & Henry & Motorised & 13 & 29 & 32 & 31 \\
\hline 26 & 4549 & 5163 & 614 & Conical v. & Henry & Motorised & 15 & 28 & 43 & 41 \\
\hline 27 & 4476 & 5379 & 903 & Conical v. & Henry & Motorised & 14 & 31 & 43 & 38 \\
\hline 28 & 3213 & 5175 & 1962 & Conical v. & Henry & Motorised & 17 & 35 & 23 & 24 \\
\hline 29 & 4554 & 5529 & 975 & Conical v. & Henry & Motorised & 22 & 32 & 26 & 22 \\
\hline 30 & 4617 & 5977 & 1360 & Conical v. & Henry & Motorised & 16 & 33 & 26 & 29 \\
\hline 31 & 2680 & 3270 & 590 & Bowl & Peter & Motorised & 5 & 29 & 29 & 33 \\
\hline 32 & 3150 & 3177 & 27 & Bowl & Peter & Motorised & 5 & 32 & 16 & 38 \\
\hline 33 & 3151 & 3617 & 466 & Bowl & Peter & Motorised & 8 & 32 & 19 & 34 \\
\hline 34 & 3971 & 4362 & 391 & Bowl & Peter & Motorised & 9 & 29 & 37 & 36 \\
\hline 35 & 3294 & 4134 & 840 & Bowl & Peter & Motorised & 8 & 32 & 45 & 40 \\
\hline 36 & 3417 & 3859 & 442 & Bowl & Peter & Motorised & 10 & 30 & 47 & 40 \\
\hline 37 & 3743 & 4146 & 403 & Bowl & Peter & Motorised & 0 & 38 & 24 & 28 \\
\hline 38 & 3658 & 4372 & 714 & Bowl & Peter & Motorised & 2 & 32 & 38 & 43 \\
\hline 39 & 3666 & 4086 & 420 & Bowl & Peter & Motorised & 8 & 35 & 28 & 30 \\
\hline 40 & 3738 & 4265 & 527 & Bowl & Peter & Motorised & 8 & 33 & 18 & 29 \\
\hline 41 & 3598 & 4154 & 556 & Bowl & Peter & Motorised & 11 & 34 & 24 & 33 \\
\hline 42 & 3871 & 4282 & 411 & Bowl & Peter & Motorised & 12 & 31 & 24 & 32 \\
\hline 43 & 3087 & 4234 & 1147 & Bowl & Peter & Motorised & 7 & 38 & 20 & 32 \\
\hline 44 & 3691 & 4187 & 496 & Bowl & Peter & Motorised & 9 & 38 & 32 & 25 \\
\hline 45 & 3727 & 4185 & 458 & Bowl & Peter & Motorised & 11 & 34 & 27 & 26 \\
\hline 46 & 4849 & 5931 & 1082 & Conical v. & Peter & Motorised & 13 & 37 & 21 & 20 \\
\hline 47 & 4885 & $5,10 \mathrm{E}+03$ & 215 & Conical v. & Peter & Motorised & 12 & 28 & 26 & 24 \\
\hline 48 & 4227 & 5013 & 786 & Conical v. & Peter & Motorised & 6 & 30 & 35 & 23 \\
\hline 49 & 4094 & 5015 & 921 & Conical v. & Peter & Motorised & 12 & 30 & 21 & 30 \\
\hline 50 & 4550 & 5016 & 466 & Conical v. & Peter & Motorised & 36 & 45 & 21 & 30 \\
\hline 51 & 4643 & 5404 & 761 & Conical v. & Peter & Motorised & 8 & 34 & 32 & 27 \\
\hline
\end{tabular}


Table 1. Orientation analysis results for experimental samples taken in tangential and radial sections. MD - Mean direction, CSD - Circular standard deviation. (Continuation)

\begin{tabular}{|c|c|c|c|c|c|c|c|c|c|c|}
\hline \multirow{2}{*}{ Sample } & \multirow{2}{*}{$\begin{array}{c}\text { Min. } \\
\text { thickness }\end{array}$} & \multirow{2}{*}{$\begin{array}{c}\text { Max. } \\
\text { thickness }\end{array}$} & \multirow{2}{*}{$\begin{array}{l}\text { Diff. in } \\
\text { thickness }\end{array}$} & \multirow{2}{*}{ Shape } & \multirow{2}{*}{ Author } & \multirow{2}{*}{ Wheel } & \multicolumn{2}{|c|}{ Radial sections } & \multicolumn{2}{|c|}{ Tangential sections } \\
\hline & & & & & & & MD & CSD & MD & CSD \\
\hline 52 & 4620 & 5395 & 775 & Conical v. & Peter & Motorised & 26 & 34 & 20 & 21 \\
\hline 53 & 4038 & 4897 & 859 & Conical v. & Peter & Motorised & 22 & 30 & 13 & 18 \\
\hline 54 & 4490 & 5162 & 672 & Conical v. & Peter & Motorised & 18 & 44 & 13 & 26 \\
\hline 55 & 5061 & $6,15 \mathrm{E}+03$ & 1091 & Conical v. & Peter & Motorised & 13 & 38 & 22 & 29 \\
\hline 56 & 4619 & 5163 & 544 & Conical v. & Peter & Motorised & 5 & 27 & 21 & 21 \\
\hline 57 & 4601 & 5274 & 673 & Conical v. & Peter & Motorised & 11 & 25 & 21 & 24 \\
\hline 58 & 3890 & 4120 & 230 & Conical v. & Peter & Motorised & 18 & 40 & 26 & 27 \\
\hline 59 & 4716 & 5365 & 649 & Conical v. & Peter & Motorised & 27 & 51 & 27 & 22 \\
\hline 60 & 4783 & 5099 & 316 & Conical v. & Peter & Motorised & 7 & 31 & 31 & 20 \\
\hline 61 & 8824 & 9686 & 862 & Conical v. & Peter & Flywheel & 21 & 34 & 17 & 35 \\
\hline 62 & 8832 & 9545 & 713 & Conical v. & Peter & Flywheel & 19 & 36 & 15 & 28 \\
\hline 63 & 8981 & 9604 & 623 & Conical v. & Peter & Flywheel & 22 & 40 & 18 & 28 \\
\hline 64 & 8493 & 10159 & 1666 & Conical v. & Peter & Flywheel & 13 & 36 & 4 & 27 \\
\hline 65 & 7870 & 8400 & 530 & Conical v. & Peter & Flywheel & 16 & 35 & 12 & 31 \\
\hline 66 & 8607 & 11098 & 2491 & Conical v. & Peter & Flywheel & 17 & 33 & 17 & 31 \\
\hline 67 & 3965 & 6019 & 2054 & Bowl & Thomas & Motorised & 10 & 30 & 6 & 41 \\
\hline 68 & 3916 & 5497 & 1581 & Bowl & Thomas & Motorised & 12 & 34 & 16 & 39 \\
\hline 69 & 3554 & 5511 & 1957 & Bowl & Thomas & Motorised & 3 & 34 & 5 & 32 \\
\hline 70 & 4216 & 6451 & 2235 & Bowl & Thomas & Motorised & 9 & 35 & 17 & 34 \\
\hline 71 & 4349 & 6475 & 2126 & Bowl & Thomas & Motorised & 18 & 33 & 11 & 32 \\
\hline 72 & 3926 & 5816 & 1890 & Bowl & Thomas & Motorised & 16 & 35 & 17 & 28 \\
\hline 73 & 3702 & 7127 & 3425 & Bowl & Thomas & Motorised & 14 & 40 & 13 & 28 \\
\hline 74 & 3947 & 6606 & 2659 & Bowl & Thomas & Motorised & 15 & 37 & 11 & 32 \\
\hline 75 & 3771 & 6335 & 2564 & Bowl & Thomas & Motorised & 23 & 36 & 11 & 32 \\
\hline 76 & 4282 & 5291 & 1009 & Bowl & Thomas & Motorised & 9 & 40 & 19 & 33 \\
\hline 77 & 4256 & 5658 & 1402 & Bowl & Thomas & Motorised & 13 & 44 & 13 & 31 \\
\hline 78 & 4364 & 6078 & 1714 & Bowl & Thomas & Motorised & 11 & 41 & 20 & 29 \\
\hline 79 & 3273 & 5742 & 2469 & Bowl & Thomas & Motorised & 8 & 32 & 7 & 36 \\
\hline 80 & 2954 & 5773 & 2819 & Bowl & Thomas & Motorised & 8 & 35 & 11 & 35 \\
\hline 81 & 3542 & 6477 & 2935 & Bowl & Thomas & Motorised & 11 & 39 & 9 & 35 \\
\hline 82 & 6513 & 8194 & 1681 & Conical v. & Thomas & Motorised & 13 & 40 & 35 & 39 \\
\hline 83 & 6219 & 7205 & 986 & Conical v. & Thomas & Motorised & 22 & 41 & 18 & 36 \\
\hline 84 & 6471 & 8063 & 1592 & Conical v. & Thomas & Motorised & 11 & 36 & 10 & 29 \\
\hline 85 & 6773 & 7352 & 579 & Conical v. & Thomas & Motorised & 15 & 40 & 17 & 37 \\
\hline 86 & 6715 & 7233 & 518 & Conical v. & Thomas & Motorised & 20 & 37 & 24 & 36 \\
\hline 87 & 7120 & 7343 & 223 & Conical v. & Thomas & Motorised & 20 & 37 & 16 & 38 \\
\hline 88 & 7179 & 8131 & 952 & Conical v. & Thomas & Motorised & 19 & 40 & 11 & 30 \\
\hline 89 & 7535 & 8166 & 631 & Conical v. & Thomas & Motorised & 16 & 41 & 29 & 37 \\
\hline 90 & 7305 & 8214 & 909 & Conical v. & Thomas & Motorised & 19 & 42 & 25 & 37 \\
\hline 91 & 6786 & 7729 & 943 & Conical v. & Thomas & Motorised & 11 & 39 & 8 & 39 \\
\hline 92 & 6775 & 7370 & 595 & Conical v. & Thomas & Motorised & 8 & 36 & 16 & 40 \\
\hline 93 & 6969 & 7340 & 371 & Conical v. & Thomas & Motorised & 8 & 36 & 18 & 34 \\
\hline 94 & 7923 & 9060 & 1137 & Conical v. & Thomas & Motorised & 8 & 35 & 14 & 28 \\
\hline 95 & 7477 & 9114 & 1637 & Conical v. & Thomas & Motorised & 21 & 33 & 22 & 30 \\
\hline 96 & 8476 & 8922 & 446 & Conical v. & Thomas & Motorised & 19 & 33 & 17 & 39 \\
\hline
\end{tabular}

JMicroVision software (Roduit, 2014). Two basic measures were chosen to express the object orientation: (a) mean direction (MD) - average orientation of objects, and (b) circular standard deviation (CSD) - the dispersion of the values from the average (Fisher, 1993, pp.75-78; Mardia and Jupp, 2000, pp.15-19).

In the first experimental collection, we found several significant markers distinguishing wheel finishing, 


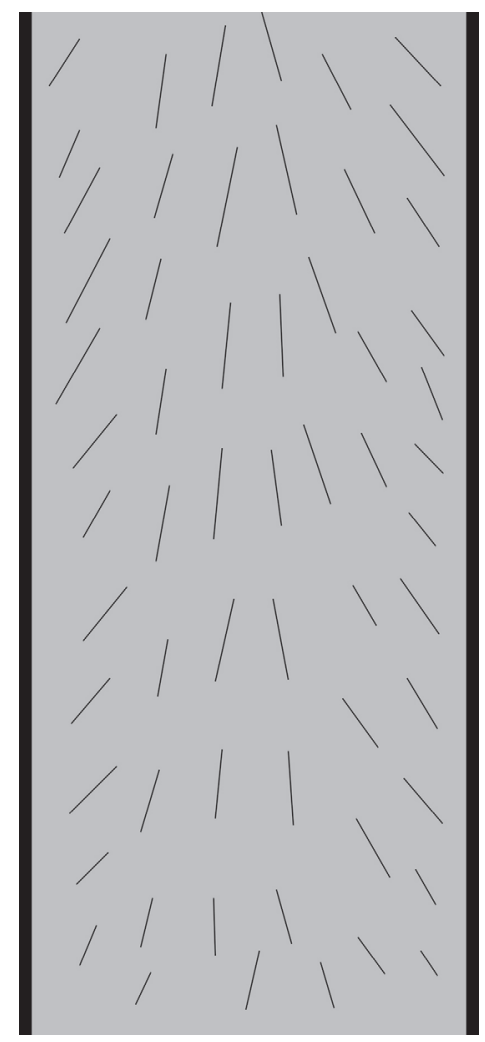

Figure 1. Imbricate pattern - orientation pattern typical for wheel throwing observed in radial sections. The upper ends of the objects in the marginal zones of wheel-thrown pottery incline inwards towards the core of the wall.

wheel shaping, and wheel throwing as basic levels of the contribution of rotational movement in pottery forming ${ }^{1}$, especially in the mean directions in core areas of radial sections, in CSD in core areas of radial sections or the mean direction in tangential sections (Thér, 2016).

In the second experimental dataset, we focused directly on the distinctions among different uses of the potter's

\footnotetext{
${ }^{1}$ There are two basic ways to classify variants of the application of rotational movement in the pottery-forming sequence. The first approach classifies individual combinations of the techniques applied at different stages of the forming. The forming methods are then referred to as, for example, wheel coiling or wheel moulding (Berg, 2009; Roux, 2019; 2017; Rückl and Jacobs, 2016; Thér and Toms, 2016). An alternative approach is to separately define the variants of the use of rotational movement and define them independently of the other techniques (Berg, 2008; 2007; Choleva, 2012; Courty and Roux, 1995; Henrickson, 1991; Roux, 2003; Roux and Courty, 1998; Thér, 2016; Thér et al., 2017; Thér and Toms, 2016). The differences in the contribution of rotational movement to the whole forming sequence are the main criterion in this classification:

(a) Wheel finishing. The vessel is formed by some hand-building technique and subsequently the rotational movement is used for surface modifications and minor shape corrections, i.e. only in the finishing stage.

(b) Wheel shaping. A roughout of the vessel is formed by some handbuilding technique and subsequently rotational kinetic energy (RKE) is used to shape and thin the vessel walls. This technique can be used in assembling and finishing the vessel.

(c) Wheel throwing. The entire forming sequence is performed using RKE. The main interest of the orientation analysis is to define the relation between the contribution of rotational movement in forming and orientation patterns: thus, we use the second approach to classification.
}

wheel. In this dataset, we evaluated the effect of the degree of transformation of the clay mass, the shape of the vessel, the velocity of rotation or the individual experience and skills of the potter. The principal finding of the analysis of the second experimental collection was that the specific characteristics of the orientation of wheel-thrown samples are developed especially in the lower parts of the vessels. The significant difference between the results obtained from lower and upper parts of the experimental vessels can be seen especially in the tangential sections. The difference is due to the fact that the lower part of the vessel undergoes a strong transformation when the potter creates a basic form prepared for lifting. While she/he lifts the clay mass upward, the rest of the clay is lifted above the fingers but is not affected by their movement (Thér and Toms, 2016, pp.38-39).

The analysis of the second experimental series also confirmed the observation made in the first experimental series, namely that the upper ends of the objects in the marginal zones of wheel-thrown pottery incline inwards towards the core of the wall (Figure 1). We called this phenomenon "imbricate pattern" and suggested that this pattern is caused by shear stress induced by upward movements of the fingers during wheel throwing. The clay mass in the margins moves more quickly during lifting than the mass in the core of the wall. Therefore, marginal zones can be seen as shear zones with a predominance of shear stress. The comparison of internal and external areas shows that the inclination of the inclusions and voids inwards is more strongly developed in the external area. We explained this phenomenon by the disproportion of the forces required on the interior and exterior of the vessel, which causes larger shear deformation on the exterior area of the vessel wall and subsequently a more pronounced imbricate pattern in this area (Thér and Toms, 2016, p.38).

In the third experimental series described in this study, we focused solely on the orientation patterns resulting from wheel throwing and especially on those variables whose significant effect became the subject of hypotheses after evaluating the previous series.

a) Above all, the shape of the vessel is important. The analysis suggested that the shape significantly influences the orientation parameters. Samples taken from the oblate ellipsoid fashioned in the second experimental series showed below-average CSD values in radial sections from the lower parts of the vessels but, more importantly, a significant increase in CSD and lesser deviation from the horizontal axis in tangential sections (Thér and Toms, 2016, Figures 5 and 7). The distortion from typical wheel-throwing values for conical shapes could be hypothetically proportional to the degree of transformation that is required to finish the shape of the vessel extra to the lifting of the clay.

b) The second experimental series also showed that the orientation patterns reflect the equilibrium established between the potter's actions and tools she/he uses during forming. If the potters use an unfamiliar clay or rotational device or throw an unusual shape, they disturb the equilibrium gained by experience and thus also the alignment typical for the 
Figure 2. Experimentally-replicated vessels' shapes with the location of tangential and radial sections.

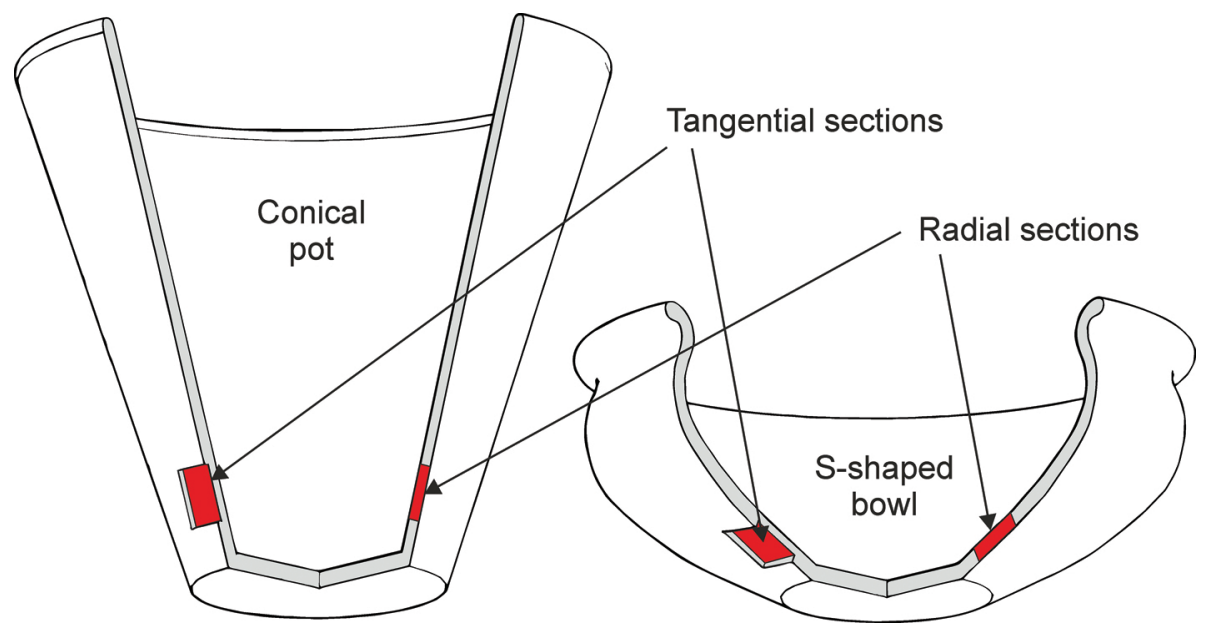

technique. This especially applies to the beginner for whom all the components of the technique are new (Thér and Toms, 2016, Figure 7). In this current, third experimental series we compared three professional potters who routinely produce pottery, to see whether the results are comparable when the potters have (a) a similar, high level of skill, (b) create shapes that do not differ significantly from what they are used to forming on a wheel, and (c) use familiar tools, i.e. potters are in equilibrium with their working environment.

\section{Materials and method}

The third experimental collection is focused on the variability of orientation patterns within the wheel-throwing method. So far, one principal experienced potter with 23 years of experience in wheel throwing, Peter Toms, was employed in our experiments. Along with Petr Toms (hereinafter referred to as Peter) we included two other professional potters: Jiří Lang (hereinafter referred to as Henry) and Tomáš Macek (hereinafter referred to as Thomas).

Two different vessel shapes were replicated: a simple conical vessel $180 \mathrm{~mm}$ in height and $200 \mathrm{~mm}$ in diameter at the top and an S-shaped bowl $85 \mathrm{~mm}$ in height and $200 \mathrm{~mm}$ in diameter at the top (depicted in Figure 2). The S-shaped bowl was chosen because, in our application of the methodology, we are dealing mainly with Late Iron Age pottery in Central Europe, and this is the most common shape of wheel-made pottery in this context.

Each potter formed 15 slightly conical pots and $15 \mathrm{~S}$-shaped bowls. The target wall thickness for all the containers was $5 \mathrm{~mm}$. No other parameters of the forming method were specified in order not to force the potters to employ motions that are not "natural" for them. All the potters used their wheels (motor-driven) and the same fine-grained commercial clay - Witgert 10 . The experimental collection was created during one session in one pottery workshop after the potters became acquainted with the selected pottery shapes. The speed of the wheels was measured by a laser tachometer.

The dataset was complemented by six conical vessels thrown by Peter on a replica of a flywheel made of a wooden- spoked wheel. The device is located in the Archaeological park of prehistory in Všestary (Czech Republic). Peter does not work on this wheel on a regular basis and there was a minor technical problem related to fitting the wheel socket in the axis which caused vibrations of the wheel when a certain speed was reached.

Two oriented thin sections were cut from the lower body of each experimental vessel: tangential and radial (Figure 2). The entire area of each thin section was recorded at a magnification of $200 \times$ using a Keyence VHX6000 digital microscope. The resultant images have a resolution of $1.11 \mu \mathrm{m}$. The analysis followed the published methodology (Thér, 2016; Thér and Toms, 2016), except for the software treatment. The components of the ceramic materials were extracted using automatic area measurement tools available in the Keyence VHX6000 measurement software. The range of threshold values chosen to separate inclusion and void representations was based primarily on colour saturation, which shows the best results for the thin sections with uneven thickness (resulting in uneven brightness of the captured image).

The extracted objects in the radial sections were analysed only in the external zones of the section (one-third of the thickness adjacent to the outer edge). The focus on the external area follows the results of the analysis of the

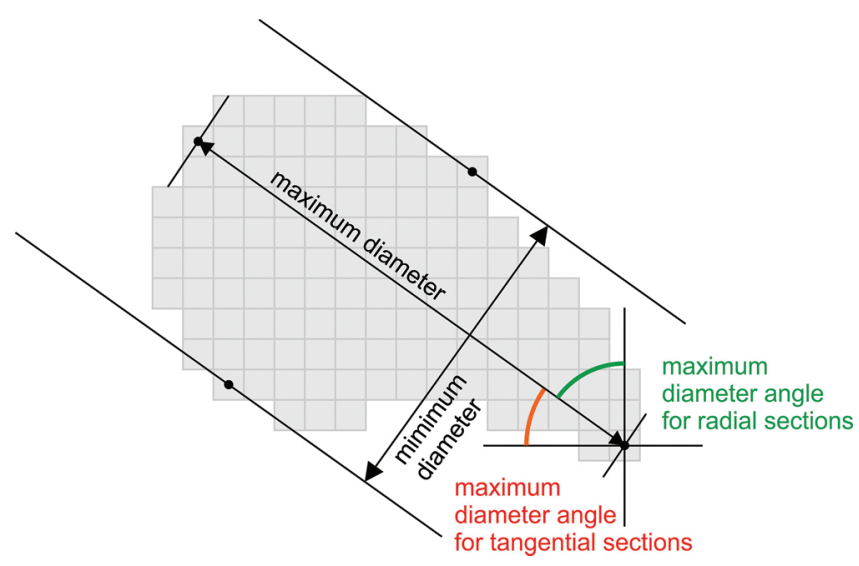

Figure 3. Descriptors of the separate objects relevant to the analysis. 


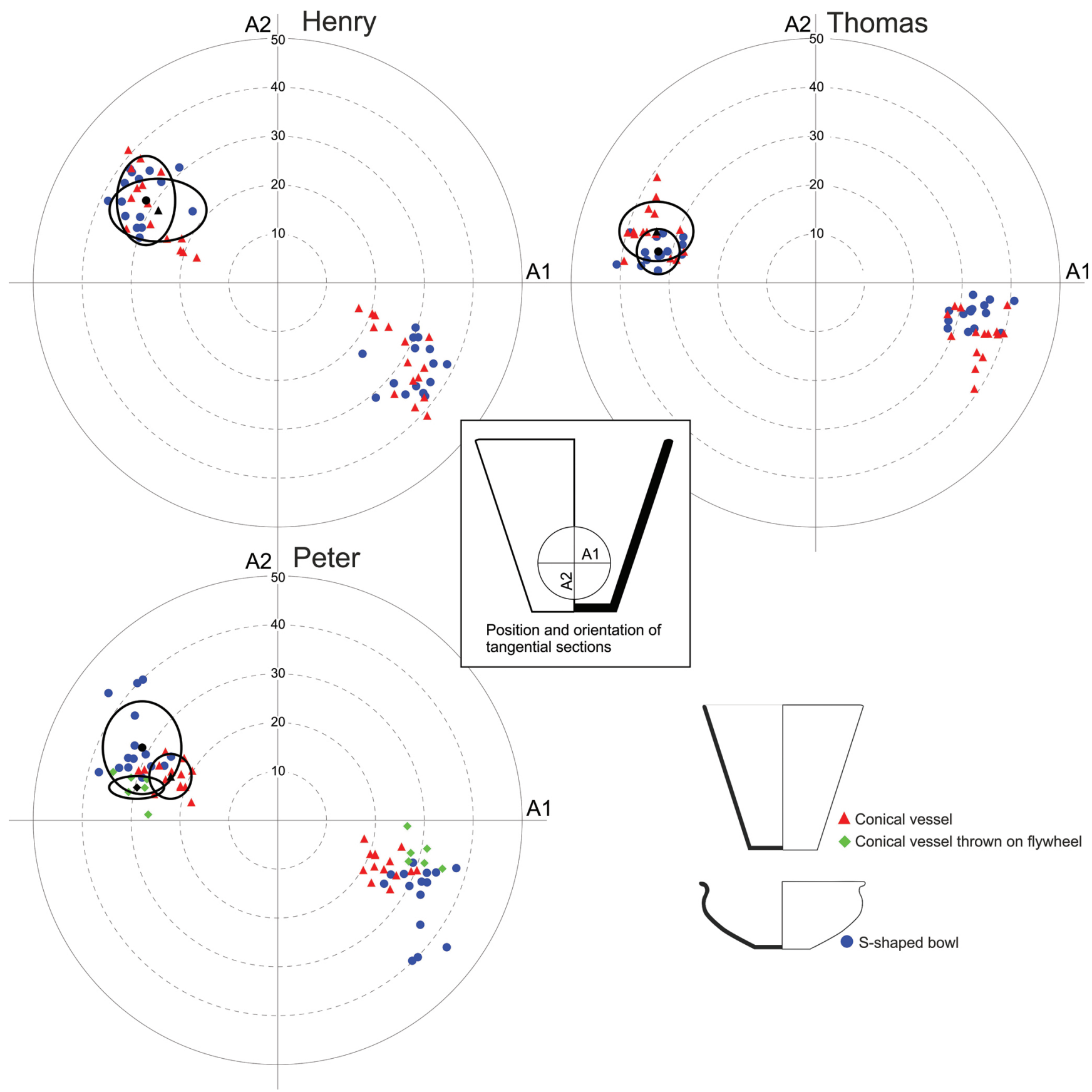

Figure 4. Orientation of inclusions and voids in tangential sections.

second experimental series which showed that the typical imbrication pattern is more strongly developed in the external area (Thér and Toms, 2016, Figure 4). The extracted objects were characterised by a set of descriptors relevant to the analysis (Figure 3): a) maximum diameter - the maximum length between any two points that lie on the inner perimeter of the object; b) minimum diameter - the minimum possible distance between two parallel lines on either side of the object, this is calculated as the distance between the pixels that each of the two lines touches; c) elongation - aspect ratio of the object (maximum diameter/minimum diameter); d) orientation - the angle between the object's maximum diameter axis and the horizontal axis read clockwise for tangential sections and the angle between the object's maximum diameter axis and the vertical axis read counterclockwise for radial sections.

Two basic measures were chosen to express the object orientation: (a) mean direction, and (b) circular standard deviation (CSD) (Fisher, 1993, pp.75-78; Mardia and Jupp, 2000, pp.15-19). The raw data are plotted in a polar coordinate system. Each point in the diagram is determined by an angle from a reference direction which represents the mean direction of the objects of the given sample and the distance from the centre of the circle which represents the CSD values. The calculated orientations are an axial type of data. Axial data consist of an undirected line - either end of 
Table 2. Descriptive statistics of orientation, alignment, and wall thickness of experimental samples according to the observed variables.

\begin{tabular}{|c|c|c|c|c|c|c|c|c|}
\hline & Potter & \multicolumn{2}{|c|}{ Henry } & \multicolumn{2}{|c|}{ Peter } & \multicolumn{3}{|c|}{ Thomas } \\
\hline & Shape & Bowl & Conical v. & Bowl & Conical v. & & Bowl & Conical v. \\
\hline & Wheel & Motorised & Motorised & Motorised & Motorised & Flywheel & Motorised & Motorised \\
\hline \multicolumn{2}{|c|}{ Number of Observations } & 15 & 15 & 15 & 15 & 6 & 15 & 15 \\
\hline \multicolumn{2}{|c|}{ Av. thickness (mm) } & 4.4 & 4.5 & 3.8 & 4.9 & 9.2 & 5 & 7.5 \\
\hline \multicolumn{2}{|c|}{ Standard deviation of thickness (mm) } & 0.5 & 0.5 & 0.3 & 0.4 & 0.5 & 0.3 & 0.6 \\
\hline \multicolumn{2}{|c|}{ Av. diference in thickness (mm) } & 0.7 & 0.9 & 0.5 & 0.7 & 1.1 & 2.2 & 0.9 \\
\hline \multirow{4}{*}{$\begin{array}{l}\text { Tangential } \\
\text { sectons }\end{array}$} & Mean Vector $(\mu)$ & 32.983 & 30.411 & 28.446 & 23.21 & 13.902 & 12.405 & 18.673 \\
\hline & Circular Standard Deviation & 8.977 & 9.185 & 9.287 & 6.108 & 5.109 & 4.487 & 7.078 \\
\hline & \multirow{2}{*}{$\begin{array}{l}99 \% \text { Confidence Interval } \\
(-/+) \text { for } \mu\end{array}$} & 26.349 & 23.623 & 21.583 & 18.695 & 6.742 & 9.087 & 13.441 \\
\hline & & 39.617 & 37.199 & 35.309 & 27.726 & 21.062 & 15.722 & 23.905 \\
\hline \multirow{5}{*}{$\begin{array}{l}\text { Radial } \\
\text { sections }\end{array}$} & Mean Vector $(\mu)$ & 3.988 & 17.306 & 7.585 & 15.473 & 17.688 & 11.976 & 15.419 \\
\hline & Circular Standard Deviation & 2.082 & 5.351 & 3.143 & 8.495 & 3.055 & 4.637 & 4.921 \\
\hline & Standard Error of Mean & 0.597 & 1.536 & 0.902 & 2.437 & 1.662 & 1.331 & 1.412 \\
\hline & \multirow{2}{*}{$\begin{array}{l}99 \% \text { Confidence Interval } \\
(-/+) \text { for } \mu\end{array}$} & 2.449 & 13.35 & 5.262 & 9.194 & 13.406 & 8.548 & 11.781 \\
\hline & & 5.527 & 21.262 & 9.909 & 21.751 & 21.97 & 15.404 & 19.057 \\
\hline
\end{tabular}

the line could be taken as the direction; therefore, the data are represented by both possible directions, i.e., each sample is plotted by a pair of points.

\section{Results}

The work of each of the potters can be characterised by a slightly different orientation pattern (all the measurements are summarised in Table 2). Peter's conical vessels show a coherent group corresponding to the previous findings in orientations and alignment in tangential sections (average deviation from horizontal axis $21^{\circ}$ and CSD $24^{\circ}$ ), the bowls exhibit similar orientation (average $\mathrm{MD} 27^{\circ}$ ), but a significant increase in $\operatorname{CSD}\left(33^{\circ}\right.$ on average) with extremes exceeding $40^{\circ}$ (Figure 4). A significant difference can also be observed in the radial sections. The conical vessels have significantly more developed inward inclination $\left(15^{\circ}\right.$ on average) compared to the bowls ( $8^{\circ}$ on average; Figure 5$)$. While the thickness of the conical vessel walls (measured in the area of the sample) roughly corresponds to the specified thickness $(4.8 \mathrm{~mm}$ on average, standard deviation of $0.4 \mathrm{~mm}$ ), the wall thickness of the bowls is significantly lower $(3.8 \mathrm{~mm}$ on average, standard deviation of $0.3 \mathrm{~mm}$; Figure 6). Throwing of pots on the flywheel results in a decrease in the deviations from the horizontal axis (average MD $16^{\circ}$, average $\operatorname{CSD} 30^{\circ}$ ). The thickness of the walls (9.2 $\mathrm{mm}$ on average, standard deviation of $0.6 \mathrm{~mm}$; Figure 6) demonstrates the difficulty that the potter encountered when using non-standard and technically-unadjusted equipment.

Conical vessels and bowls cannot be reliably differentiated in the production by Henry. Both show a higher average deviation from the horizontal axis (average MD: conical v. $31^{\circ}$, bowls $34^{\circ}$ ) than Peter's vessels. The average CSD is similar (conical v. $33^{\circ}$, bowls $34^{\circ}$ ) and comparable with the bowls produced by Peter. Only a small proportion of the conical vessels exhibit CSD below $30^{\circ}$ (Figure 4). In contrast, there is a difference in the inward inclination between conical vessels and bowls in the radial sections. The difference is similar to that of Peter's samples but more pronounced: conical vessels $-17^{\circ}$ on average, bowls $-4^{\circ}$ on average (Figure 5). The wall thickness of the conical vessels ( $4.5 \mathrm{~mm}$ on average, standard deviation of $0.5 \mathrm{~mm}$ ) and bowls ( $4.4 \mathrm{~mm}$ on average, standard deviation of $0.5 \mathrm{~mm}$ ) is similar and corresponds with the assigned thickness (Figure 6).

Both the shapes fashioned by Thomas show lower mean deviation from the horizontal axis than the vessels fashioned by the previous two potters and there is a significant difference between them in this respect. The bowls exhibit lower deviation than the conical vessels (conical v. $17^{\circ}$ on average, bowls $11^{\circ}$ on average). Thomas' vessels are very similar in alignment (average CSD: conical v. $33^{\circ}$, bowls $34^{\circ}$ ) to those of Henry (Figure 4). No significant difference can be seen in the radial sections: the average MD of the conical vessels is $15^{\circ}$ and bowls $12^{\circ}$ (Figure 5). The conical vessels are significantly thicker than required $(7.5 \mathrm{~mm}$ on average, standard deviation of $0.6 \mathrm{~mm}$ ). The bowls have an average thickness of $4.9 \mathrm{~mm}$ (standard deviation of $0.3 \mathrm{~mm}$; Figure 6). The significantly higher difference in the wall thickness compared to other assemblages reflects the unevenness of the walls in the lower parts of the bowls (the walls taper upwards; Figure 7).

\section{Discussion}

The results point to interesting differences among the potters. All three potters came from different learning environments. They used motor-driven potter's wheels (except for the manually-driven flywheel). Peter and Henry 


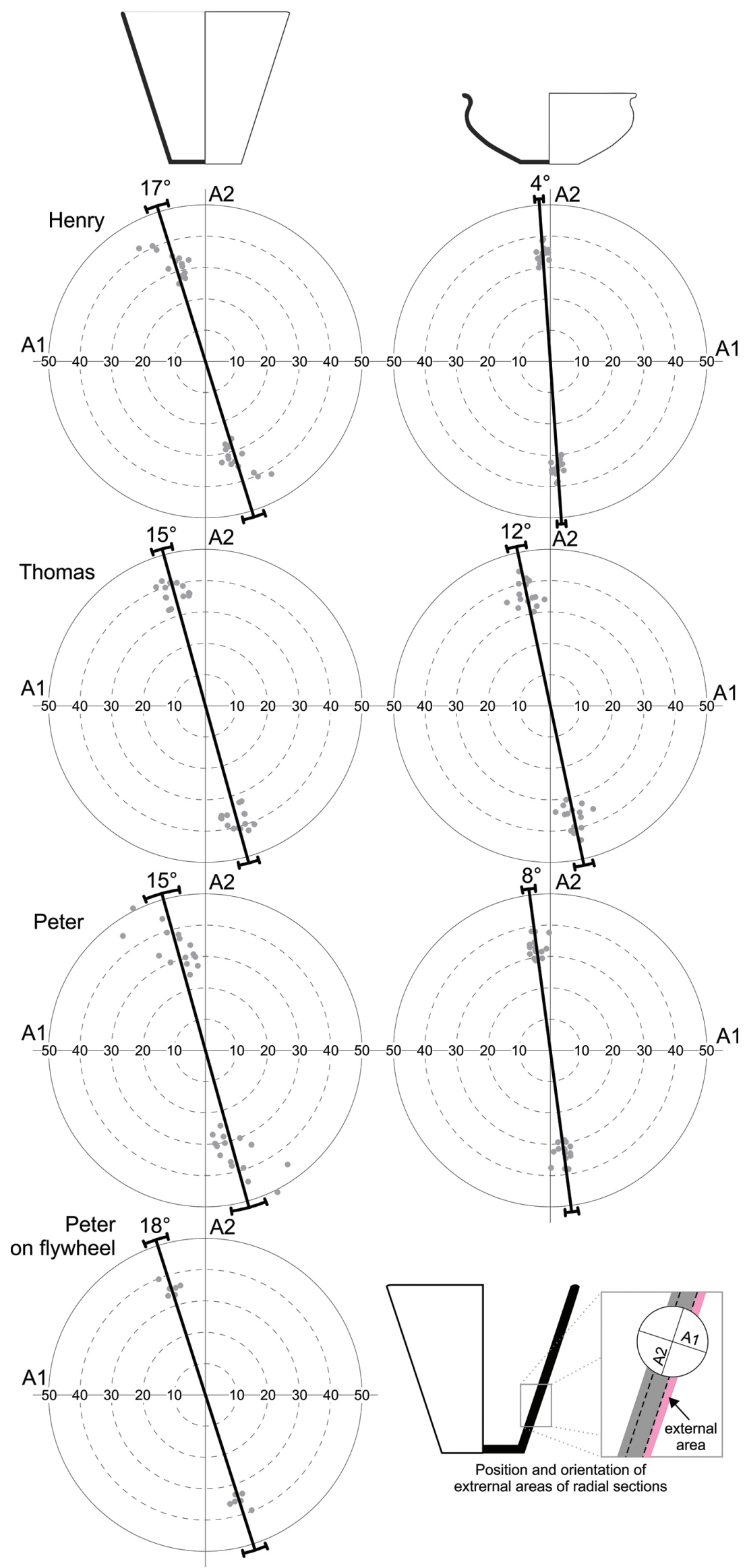

Figure 5. Orientation of inclusions and voids in radial sections. 
Figure 6. Wall thickness in the sample location. JLB - bowls thrown by Henry; JLC - conical vessels thrown by Henry; PTB - bowls thrown by Peter; PTC - conical vessels thrown by Peter; PTF - conical vessels thrown by Peter on a flywheel; TMB - bowls thrown by Thomas; TMC - conical vessels thrown by Thomas.

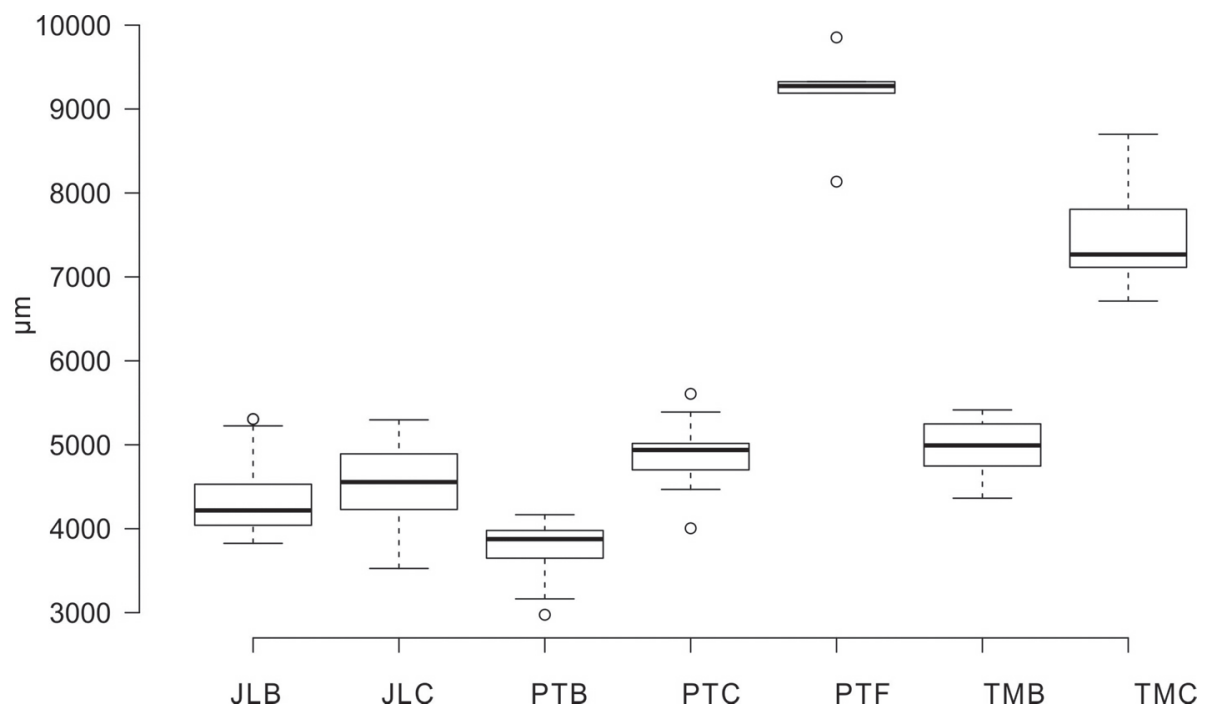

used wheel variants with a motorised flywheel which makes the regulation of rotation speed more difficult. Their performance is closer to kick wheels with characteristic speed oscillations. Thomas used a direct-drive wheel where the wheelhead is directly connected to the motor and speed is regulated by the foot pedal allowing maintenance of constant rotation speed. There were no apparent differences in their throwing styles with one slight exception which will be discussed later. Progress of wheel velocity during forming and time spent on manufacture was measured (Figure 8). Peter works significantly faster than the other two potters with lower wheel velocity (thus his work is the most efficient in terms of energy expenditure). The need for fewer moves to achieve the same shape is reflected by the low CSD in the tangential sections of samples taken from Peter's conical vessels compared to the other conical vessels. The bowls were generally thrown in a shorter time because of their smaller size. More interestingly, the velocity decreases more rapidly during the forming of bowls than of conical shapes. The wider shapes require more careful lifting to prevent disruption or collapse of the shape.
The effect of the shape is partially independent of an individual's throwing style and experience. The observed phenomena basically conform to the results of analysis of the second experimental collection: the more intricate the shape, the greater the transformation (or disruption of typical orientation). However, the effects vary from potter to potter. The distortion from typical wheel-throwing values for conical shapes could be hypothetically proportional to the degree of transformation from the roughout to the final shape. A roughout is formed in the first stage of throwing. In this stage, all the basic lifting of the clay mass is completed. Lifting causes development of the orientation patterns typical for wheel throwing. In the subsequent stage, the lifted clay mass is transformed into the required shape. This transformation is performed while the wheel is still spinning; pressure is combined with rotational energy, which theoretically causes (a) thinning of the vessel wall, (b) transformation of the object orientation resulting in lowering of the average angle (reorientation towards the horizontal axis) and an increase in CSD in the tangential section, and (c) greater parallel alignment of the objects to
Figure 7. Difference in wall thickness in the sample location. JLB - bowls thrown by Henry; JLC - conical vessels thrown by Henry; PTB - bowls thrown by Peter; PTC - conical vessels thrown by Peter; PTF - conical vessels thrown by Peter on a flywheel; TMB - bowls thrown by Thomas; $\mathrm{TMC}$ - conical vessels thrown by Thomas.

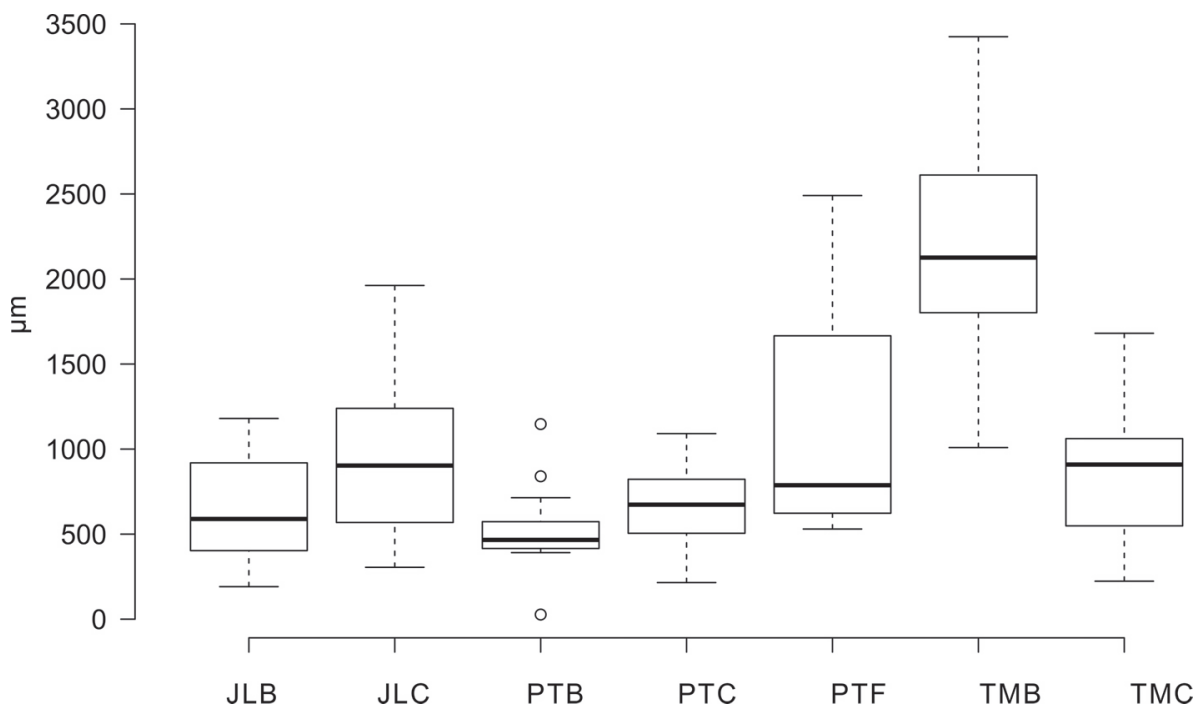


the wall axis in perpendicular sections, i.e., less profound imbrication patterns. However, there is another way to form more intricate shapes. For some potters, the distinction between the lifting of a roughout and its transformation into a final shape is rather theoretical. They continue lifting while forming the final shape and the two phases are not strictly separated. This approach is essential to achieving regular wall thickness. Consequently, in these cases, the orientation should not be strongly affected by the further transformation of the body.

All three potters involved in this experiment first throw the conical roughout and then widen it into the shape of a bowl. However, while Peter and Henry begin to widen the shape in the relatively early stage of the throwing, Thomas keeps the shape closed significantly longer. The potters demonstrate three different sets of effects, reflecting different throwing styles or skills. Peter's bowls are $23 \%$ thinner than his conical vessels (Figure 6). A significant increase in CSD in the tangential sections (Figure 4) was observed with a decrease in the inward inclination in the radial sections (Figure 5). On the other hand, the bowls show a similar deviation from the horizontal plane as the conical shapes (Figure 4). The thickness of Henry's bowls is similar to that of his conical vessels (Figure 6). There is no significant difference in object orientation in the tangential sections (neither in MD, nor in CSD), but Henry's bowls and conical vessels show the highest difference in inward inclination in the radial sections (Figure 5). Thomas's bowls are 34\% thinner than his conical vessels (Figure 6) and the wall thickness is very uneven (Figure 7). Significantly lower deviation from the horizontal axis was observed, but no increase in CSD (Figure 4) and there is also no significant difference in orientation in the radial sections (Figure 5). None of the described patterns can be unequivocally related to the hypothetical effects of different throwing habits. For example, the lower deviation from the horizontal axis in the case of Thomas's bowls and the difference in thickness compared to conical vessels could be attributed to his habit of keeping the shape closed till the final stage of throwing, but there is no increase in CSD in tangential sections or decrease in imbrication pattern in radial sections.

The potter's experience is reflected indirectly by the deviation from the specified parameters of the experimental forming. The thicker walls of the conical shapes and uneven thickness of the bowl's walls testify to the fact that Thomas had difficulty achieving the required parameters. This corresponds with the observation (not exactly measured) that the shapes of Thomas's vessels visibly deviated from the template vessels. Thomas confirmed that, at the time of the experiment, he did not throw pottery regularly and intensively and consequently he lacked a corresponding routine. Also, the thickness of the conical vessels thrown on the flywheel reflects Peter's lack of familiarity with this type of wheel and probably also the technical problems associated with the device, causing unstable rotation. In both cases, lower deviation of the object orientation from the horizontal axis is characteristic. Consequently, this effect cannot be associated either with the vessel shape itself or with any other considered variables, e.g., speed of the rotation.

The results of the analysis of this experimental dataset have significant consequences for the application of this methodology to archaeological pottery. The idea that the orientation pattern is consistent for wheel throwing in general (as for a forming method highly constrained by the forces employed during forming) irrespective of the potters' individual motor habits is no longer valid. The results show that we have to consider a wider range of the orientation values for wheel throwing and there is a partial overlap of values with combined forming methods. The measurements on tangential sections showing the deviation from a horizontal plane ranging between $15-35^{\circ}$ and CSD $20-30^{\circ}$ can be reliably interpreted as a result of wheel throwing. These intervals delimit the zone into which no data from other experimentally-tested forming methods have entered (Thér and Toms, 2016, Figure 6). However, CSD measurement results ranging between $30-40^{\circ}$ cannot

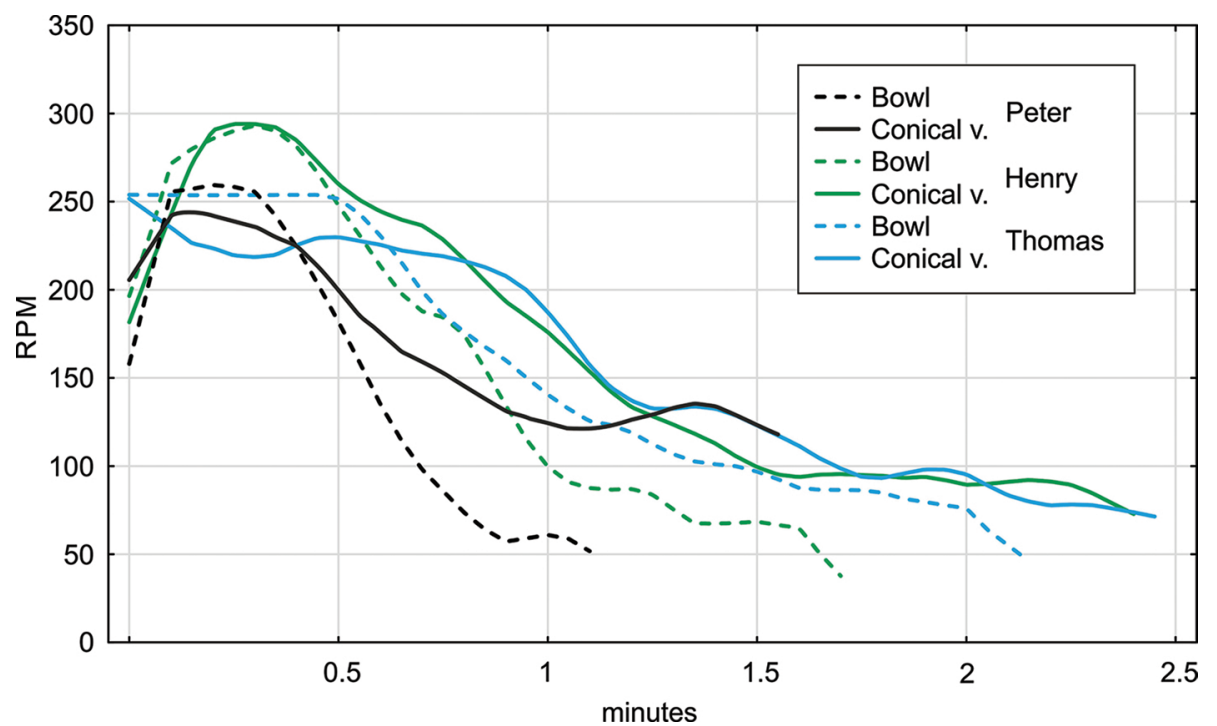

Figure 8. Averaged development of velocity of rotation of the wheels used by the potters in the experimental replication. 
be interpreted unambiguously as they may reflect both an individual throwing style and combined techniques employing wheel shaping. In this case, evidence independent of orientation measurements is required to distinguish between the two variants of the potter's wheel contribution. Apart from traditional macrotrace analysis (Arnold, 1993; Choleva, 2012; Doherty, 2015; Dupont-Delaleuf, 2011; Gelbert, 1994; Jeffra, 2013; Knappett, 1999; Méry et al., 2012; Roux, 2019; 1994; Roux and Courty, 1998; Rückl and Jacobs, 2016), which has limited value in that the technological context where the wheel-made pottery is made of fine-grained ceramic materials and the surface is carefully finished, we suggest combining two scales of structural analysis. The microscale imaging that reaches a resolution of a few micrometres can effectively capture an area of $2 \mathrm{~cm}^{2}$, which is given by (a) the size of thin sections and the limitations in positioning planar tangential sections within curved vessel walls or (b) computed tomography limits in the combination of resolution and size of the samples. This type of analysis allows an accurate estimate of inclusion and void orientation, but only locally. We propose to combine microscale analysis with imaging at a smaller scale to capture a larger area of the sample. At this scale, the accurate measurement of orientation is complicated, especially when analysing fine-grained ceramics, but other structural features can be observed, especially structural discontinuities reflecting segmental forming techniques (Thér, 2020). By such a combination, the potential to differentiate individual techniques will be increased and, given the results of the described analysis, we can consider tracking the throwing (or more generally forming) style of potters based on structural analysis of their products. The most suitable technique for imaging the structure on a smaller scale seems to be computed tomography (Bernardini et al., 2019; Gibbs, 2008; Gomart et al., 2017; Kahl and Ramminger, 2012; Karl et al., 2014; Kozatsas et al., 2018; Kulkova and Kulkov, 2016; Machado et al., 2013; Sanger et al., 2013; Sanger, 2016).

\section{Conclusion}

Analysis of the experimental collection of pottery made by three professional potters using wheel throwing revealed imprints of individual motor habits captured by the orientation analysis. It draws attention to the significance of individual style or the specifics of individual motor habits in technological studies. The analysis demonstrates that the individual motor habits can significantly affect the orientational pattern even for a forming method that seems to be very deterministic in terms of the forces employed during forming. More attention must be paid in the future to identification and description of the diversity of the modalities of wheel throwing and subsequent determination of their effects in the archaeological record. This will help to define the limits of this forming method (and especially the limits of its effects observable in the archaeological record), which is crucial both for its distinction from other forming methods utilising rotational movement and for understanding the dynamics of the evolution of wheel throwing.

\section{Acknowledgements}

The research described in this paper was completed with support from the project "Technological changes in pottery manufacture in the context of social transformations during the La Tène period in Bohemia" (project 19-21146S), financed by the Czech Science Foundation. We would like to thank Madeleine Štulíková for her assistance in correcting the English grammar and to Ina Berg, Caroline Jeffra, and Chase A. M. Minos for their helpful comments.

\section{References}

ARNOLD, D., 1993. Techniques and traditions of manufacture in the pottery of ancient Egypt. In: D. Arnold, J. Bourriau, eds. An Introduction to Ancient Egyptian Pottery. Mainz am Rhein: Von Zabern, pp. 11-102.

BALFET, H., 1953. Note sur le façonnage des poteries préhistoriques. Bulletin Société Préhistorique Française, 50, 211-217. DOI: 10.3406/ bspf.1953.3031

BERG, I., 2009. X-radiography of Knossian Bronze Age vessels: assessing our knowledge of primary forming techniques. Annual of the British School at Athens, 104, 137-173.

BERG, I., 2008. Looking through pots: recent advances in ceramics X-radiography. Journal of Archaeological Science, 35, 1177-1188. DOI: 10.1016/j.jas.2007.08.006

BERG, I., 2007. Meaning in the making: the potter's wheel at Phylakopi, Melos (Greece). Journal of Anthropological Archaeology, 26, 234-252. DOI: $10.1016 /$ j.jaa.2006.10.001

BERNARDINI, F., TUNIZ, C., ZANINI, F., 2019. X-Ray computed microtomography for paleoanthropology, archaeology, and cultural heritage. In: G. Lazzara, R. Fakhrullin, eds. Nanotechnologies and Nanomaterials for Diagnostic, Conservation and Restoration of Cultural Heritage, Advanced Nanomaterials. Elsevier, pp. 25-45. DOI : 10.1016/ B978-0-12-813910-3.00002-1

BORDET, P., COURTOIS, L., 1967. Etude géologique des céramiques anciennes. Les techniques de fabrication. Comptes rendus de l'Académie de Science, Paris, 265 D, 1665-1667.

CARR, C., 1990. Advances in ceramic radiography and analysis: applications and potentials. Journal of Archaeological Science, 17, 1334. DOI: 10.1016/0305-4403(90)90013-U

CHOLEVA, M., 2012. The first wheelmade pottery at Lerna: wheel-thrown or wheel-fashioned? Hesperia, Journal of the American School of Classical Studies at Athens, 81, 343-381. DOI: 10.2972/hesperia.81.3.0343

COURTY, M.A., ROUX, V., 1995. Identification of wheel throwing on the basis of ceramic surface features and microfabrics. Journal of Archaeological Science, 22, 17-50. DOI: 10.1016/S0305-4403(95)801618

DOHERTY, S.K., 2015. Origins and use of the potter's wheel in ancient Egypt. Oxford: Archaeopress.

DUPONT-DELALEUF, A., 2011. Styles techniques des céramiques de la protohistoire en Asie Centrale : méthodologie et études de cas. Unpublished thesis ( $\mathrm{PhD})$, Université Paris Ouest La Défense, Paris.

FELTS, W.M., 1942. A petrographic examination of potsherds from ancient Troy. American Journal of Archaeology, 46, 237-244. DOI: $10.2307 / 499386$

FISHER, N.I., 1993. Statistical analysis of circular data. Cambridge, New York: Cambridge University Press.

GELBERT, A., 1994. Tour et tournette en Espagne : recherche de macrotraces significatives des différentes techniques et méthodes de façonnage. In: F. Audouze, D. Binder, eds. Terre Cuite et Société. La Céramique, Document Technique, Économique, Culturel. Juan-les-Pins: 
APDCA, pp. 59-74.

GIBBS, K.T., 2008. Understanding community: a comparison of three Late Neolithic pottery assemblages from Wadi Ziqlab, Jordan. Unpublished thesis (PhD), University of Toronto.

GIFFORD, E.W., 1928. Pottery-making in the Southwest. Berkeley, California: University of California Press.

GOMART, L., WEINER, A., GABRIELE, M., DURRENMATH, G., SORIN, S., ANGELI, L., COLOMBO, M., FABBRI, C., MAGGI, R., PANELLIO, C., PISANI, D.F., RADI, G., TOZZI, C., BINDER, D., 2017. Spiralled patchwork in pottery manufacture and the introduction of farming to Southern Europe. Antiquity, 91, 1501-1514. DOI: 10.15184/ aqy.2017.187

HENRICKSON, R.C., 1991. Wheelmade or wheel-finished? Interpretation of 'wheelmarks' on pottery. In: J.R. Druzik, P.B. Vandiver, G. Wheeler, eds. Materials Issues in Art and Archaeology II. Pittsburgh: Materials Research Society, pp. 523-541.

JEFFRA, C.D., 2013. A re-examination of early wheel potting in Crete. The Annual of the British School at Athens, 108, 31-49. DOI: 10.1017/ S0068245413000038

KAHL, W.-A., RAMMINGER, B., 2012. Non-destructive fabric analysis of prehistoric pottery using high-resolution X-ray microtomography: a pilot study on the late Mesolithic to Neolithic site Hamburg-Boberg. Journal of the Archaeological Science, 39, 2206-2219. DOI: 10.1016/j. jas.2012.02.029

KARL, S., JUNGBLUT, D., MARA, H., WITTUM, G., KRÖMKER, S., 2014. Insights into manufacturing techniques of archaeological pottery: industrial X-ray computed tomography as a tool in the examination of cultural material. In: Craft and Science: International Perspectives on Archaeological Ceramics. $10^{\text {th }}$ European Meeting on Ancient Ceramics (EMAC '09), London, 10.-13.09.2009. UCL Qatar Series in Archaeology and Cultural Heritage. pp. 253-261.

KNAPPETT, C., 1999. Tradition and innovation in pottery forming technology: wheel-throwing at Middle Minoan Knossos. The Annual of the British School at Athens, 94, 101-129.

KOZATSAS, J., KOTSAKIS, K., SAGRIS, D., DAVID, K., 2018. Inside out: assessing pottery forming techniques with micro-CT scanning. An example from Middle Neolithic Thessaly. Journal of Archaeological Science, 100, 102-119. DOI: 10.1016/j.jas.2018.10.007

KULKOVA, M., KULKOV, A., 2016. The identification of organic temper in Neolithic pottery from Russia and Belarus. Old Potter's Alm, 21, 2-12.

LINNÉ, S., 1925. The technique of South American ceramics. Göteborg: Erlanders.

LIVINGSTONE SMITH, A., 2007. Chaîne opératoire de la poterie: références ethnographiques, analyses et reconstitution. Tervuren: Musée royal de l'Afrique centrale.

MACHADO, A.C., FREITAS, R., CALZA, C.F., LOPES, R.T., LIMA, I., CARVALHO, D.D., GASPAR, M.D., 2013. Characterization of ceramic archaeological by high resolution $\mathrm{X}$ ray microtomography. In: The Benefits of Nuclear Technology for Social Inclusion. International Nuclear Atlantic Conference. Recife: Associação Brazilieira de Energia Nuclear.

MARDIA, K.V., JUPP, P.E., 2000. Directional statistics. Chichester, New York: J. Wiley.

MÉRY, S., DUPONT-DELALEUF, A., van der LEEUW, S.E., 2012. Les techniques de façonnage céramique mettant en jeu la rotation à Hili (Émirats arabes unis) à la fin du IIIe millénaire (âge du Bronze ancien). Les nouvelles de l'Archéologie, 119, 52-64.

MIDDLETON, A., 2005. Ceramics. In: J. Lang, A. Middleton, eds. Radiography of Cultural Material. Oxford, Burlington: Elsevier, pp. 76-95.

PIERRET, A., 1995. Analyse technologique des céramiques archéologiques développements méthodologiques pour l'identification des techniques de façonnage. Un exemple d'application : le matériel du village des
Arènes à Levroux (Indre). Unpublished thesis (Ph.D). Université Paris 1 - Panthéon Sorbonne.

RODUIT, N., 2014. JMicroVision: Image analysis toolbox for measuring and quantifying components of high-definition images, version 1.2.7. http://www.jmicrovision.com/ (accessed 2.2.14).

ROUX, V., 2019. Ceramics and society: a technological approach to archaeological assemblages. Cham: Springer. DOI: 10.1007/978-3-03003973-8

ROUX, V., 2017. Ceramic manufacture: the chaîne opératoire approach. In: A.M.W. Hunt, ed. The Oxford Handbook of Archaeological Ceramic Analysis. Oxford: Oxford University Press, pp. 101-114.

ROUX, V., 2003. A dynamic systems framework for studying technological change: application to the emergence of the potter's wheel in the southern Levant. Journal of Archaeological Method and Theory, 10, 1-30. DOI: 10.1023/A:1022869912427

ROUX, V., 1994. La technique du tournage: définition et reconnaissance par les macrotraces. In: F. Audouze, D. Binder, eds. Terre Cuite et Société. La Céramique, Document Technique, Économique, Culturel. Juan-les-Pins: APDCA, pp. 45-58.

ROUX, V., COURTY, M.A., 1998. Identification of wheel-fashioning methods: technological analysis of $4^{\text {th }}-3^{\text {rd }}$ millennium oriental ceramics. Journal of Archaeological Science, 25, 747-763. DOI: 10.1006/ jasc. 1997.0219

RÜCKL, Š., JACOBS, L., 2016. "With a little help from my wheel": wheel-coiled pottery in Protogeometric Greece. Hesperia, Journal of the American School of Classical Studies at Athens, 85, 297-321. DOI: 10.2972/hesperia.85.2.0297

RYE, O.S., 1981. Pottery technology: principles and reconstruction. Washington, D.C.: Taraxacum.

SANGER, M., THOSTESON, J., HIL, M., CAIN, H., 2013. Fibrous twists and turns: early ceramic technology revealed through computed tomography. Applied Physics, A 111, 829-839. DOI: 10.1007/s00339012-7287-6

SANGER, M.C., 2016. Investigating pottery vessel manufacturing techniques using radiographic imaging and computed tomography: Studies from the Late Archaic American Southeast. Journal of Archaeological Science, Reports, 9, 586-598. DOI: 10.1016/j.jasrep.2016.08.005

SHEPARD, A.O., 1956. Ceramics for the archaeologist. Washington, D.C.: Carnegie Institution of Washington.

THÉR, R., 2020. Ceramic technology. How to reconstruct and describe pottery-forming practices. Archaeological and Anthropological Sciences, 12, 172. DOI: 10.1007/s12520-020-01131-0

THÉR, R., 2016. Identification of pottery-forming techniques using quantitative analysis of the orientation of inclusions and voids in thin sections. Archaeometry, 58, 222-238. DOI: 10.1111/arcm.12166

THÉR, R., KVĚTINA, P., NEUMANNOVÁ, K., 2019. Coiling or slab building: Potential of orientation analysis for identification of forming techniques used by Early Neolithic potters. Journal of Archaeological Science, Reports, 26, 1-14. DOI: 10.1016/j.jasrep.2019.101877

THÉR, R., MANGEL, T., GREGOR, M., 2017. Potter's wheel in the Iron Age in Central Europe: process or product innovation? Journal of Archaeological Method and Theory, 1-44. DOI: 10.1007/s10816-0169312-0

THÉR, R., TOMS, P., 2016. Quantification of the orientation and alignment of aplastic components of a ceramic body as a method for distinguishing among various means of using a rotational device in pottery forming. Journal of Archaeological Science, Reports, 9, 33-43. DOI: 10.1016/j. jasrep.2016.06.048

WHITBREAD, I.K., 1996. Detection and interpretation of preferred orientation in ceramic thin sections. In: T. Higgins, P. Main, J. Lang, eds. Imaging the Past: Electronic Imaging and Computer Graphics in Museums and Archaeology, Occasional Paper. London: British Museum, pp. 173-181. 